\title{
OPEN Applying species distribution models in public health research by predicting snakebite risk using venomous snakes' habitat suitability as an indicating factor
}

\author{
Masoud Yousefi ${ }^{1}$, Anooshe Kafash ${ }^{1 凶}$, Ali Khani ${ }^{2} \&$ Nima Nabati $^{3}$
}

Snakebite envenoming is an important public health problem in Iran, despite its risk not being quantified. This study aims to use venomous snakes' habitat suitability as an indicator of snakebite risk, to identify high-priority areas for snakebite management across the country. Thus, an ensemble approach using five distribution modelling methods: Generalized Boosted Models, Generalized Additive Models, Maximum Entropy Modelling, Generalized Linear Models, and Random Forest was applied to produce a spatial snakebite risk model for Iran. To achieve this, four venomous snakes' habitat suitability (Macrovipera lebetinus, Echis carinatus, Pseudocerastes persicus and Naja oxiana) were modelled and then multiplied. These medically important snakes are responsible for the most snakebite incidents in Iran. Multiplying habitat suitability models of the four snakes showed that the northeast of Iran (west of Khorasan-e-Razavi province) has the highest snakebite risk in the country. In addition, villages that were at risk of envenoming from the four snakes were identified. Results revealed that 51,112 villages are at risk of envenoming from $M$. lebetinus, 30,339 from E. carinatus, 51,657 from $P$. persicus and 12,124 from $N$. oxiana. Precipitation seasonality was identified as the most important variable influencing distribution of the P. persicus, $E$. carinatus and $M$. lebetinus in Iran. Precipitation of the driest quarter was the most important predictor of suitable habitats of the $N$. oxiana. Since climatic variables play an important role in shaping the distribution of the four venomous snakes in Iran, thus their distribution may alter with changing climate. This paper demonstrates application of species distribution modelling in public health research and identified potential snakebite risk areas in Iran by using venomous snakes' habitat suitability models as an indicating factor. Results of this study can be used in snakebite and human-snake conflict management in Iran. We recommend increasing public awareness of snakebite envenoming and education of local people in areas which identified with the highest snakebite risk.

Snakebite envenoming is known as an important public health problem and the cause of medical emergencies around the globe ${ }^{1-14}$. On Earth, between 421,000 and 1.2 million people are envenomed by venomous snakes annually and around 125,000 deaths per year are attributable to snakebite envenoming ${ }^{1,6,14,15}$. Snakebite envenoming is mostly described as a neglected public health issue in the tropics ${ }^{2,6,16,17}$, however, it is also an important challenge for public health in temperate areas like $\operatorname{Iran}^{18}$.

Iran is home to 81 snake species $^{14,19}$ of which 25 are venomous (Nine species are sea snakes and 16 species are terrestrial snakes). Macrovipera lebetinus (Linnaeus, 1758), Echis carinatus (Schneider, 1801), Pseudocerastes persicus (Duméril, Bibron \& Duméril, 1854) and Naja oxiana (Eichwald, 1831) are widespread in Iran and are responsible for the most snakebite incidents in the country ${ }^{18,20}$. A study reported 53,787 cases of snake bites between 2002 and 2011 in $\operatorname{Iran}^{18}$. Despite considerable research into the phylogeny, taxonomy, morphology and ecology of venomous snakes in $\operatorname{Iran}^{21-28}$ snakebite envenoming has received less attention ${ }^{18,29}$. In fact, snakebite

\footnotetext{
${ }^{1}$ Department of Environmental Science, Faculty of Natural Resources, University of Tehran, Karaj, Iran. ${ }^{2}$ Khorasan-e-Razavi Provincial Office of the Department of the Environment, Mashhad, Iran. ${ }^{3}$ Shahid Sadoughi Hospital, Shahid Sadoughi University of Medical Sciences, Yazd, Iran. ${ }^{\varpi}$ email: anooshe.kafash@ gmail.com
} 
is an important uninvestigated public health problem and conservation challenge in Iran $^{30-32}$. Thus, more effort should be made to identify areas with high snakebite risk and reduce envenoming risk from snakes.

Species Distribution Models (SDMs) have found an important application in biodiversity research ${ }^{33-35}$. They are employed in studying habitat suitability ${ }^{36-38}$, identifying environmental drivers of species distribution ${ }^{39-44}$ and predicting impacts of climate change on biodiversity ${ }^{45-50}$. Species distribution models are successfully used to identify suitable habitats of species even in areas with no distribution records $\mathrm{s}^{51-55}$. Thus, these models can be used to identify suitable habitats of venomous snakes as proxies of snakebite risk ${ }^{12,56-58}$ in data poor regions like Iran.

The main goal of this paper was to apply SDMs and produce a spatial risk model for snakebite in Iran. Five distribution modelling methods ${ }^{35}$ and distribution data of $M$. lebetinus, E. carinatus, $P$. persicus and N. oxiana were used to produce their habitat suitability models. Then, the five habitat suitability models of each species were combined by ensemble approach ${ }^{59}$ and finally the four species ensemble models were multiplied to identify potential snakebite risk. We also determined a number of villages whose population are at risk of envenoming by these four snakes in Iran. Since it believed that E. carinatus is responsible for the most mortality and morbidity cases of snake bite in $\operatorname{Iran}^{18}$ we hypothesized that more villages are at risk of envenoming form E. carinatus compared to M. lebetinus, P. persicus and N. oxiana.

\section{Results}

Model performance. All models developed in this study performed well based on the three model performance evaluation metrics, AUC, TSS and Boyce index (see plates a in Figs. 1, 2, 3, 4).

Habitat suitability of Echis carinatus. Based on ensemble model, southern part of Iran, north of Persian Gulf and vast areas in central parts of the country are identified to have highest suitability for E. carinatus (Fig. 1). Precipitation seasonality and NDVI were the most important determinant of habitat suitability of the species across the country.

Habitat suitability of Macrovipera lebetinus. The most suitable habitats of M. lebetinus are located in the Zagros Mountains, Alborz Mountains, Kopat-Dagh Mountains as well as in some isolated mountains in central Iran (Fig. 2). Precipitation seasonality, precipitation of the driest quarter, and human footprint were the most important predictors of suitable habitats for the species.

Habitat suitability of Pseudocerastes persicus. Central, southwest and northeast of Iran have highest habitat suitability for P. persicus. While, northern parts of the country are not suitable for this species (Fig. 3). Results showed that precipitation seasonality and NDVI were the most important determinant of habitat suitability of the species across Iran.

Habitat suitability of Naja oxiana. Naja oxiana's the most suitable habitats are located in northeast Iran around Kopat-Dagh Mountains as well as some isolated patches in eastern parts of the country (Fig. 4). Precipitation of the driest quarter was the most important predictor of suitable habitats of the species.

Snakebite risk model. The four venomous snakes' ensemble habitat suitability models were combined to develop a snakebite risk model for Iran (Fig. 5). Results showed that Khorasan-e-Razavi, east of Semnan, north of Khorasan-e-Jonobi and south of Khorasan-e-Shomali provinces have highest snakebite risk in Iran. West of Khorasan-e-Razavi province has high suitability for the four venomous snakes.

Villages at risk of envenoming. Number of villages that are at the risk of envenoming by each of the four snakes (Table 1, Fig. 6) were determined. Results revealed that 51,112 villages are at risk of envenoming from $M$. lebetinus, 30,339 from E. carinatus, 51,657 from P. persicus and 12,124 from N. oxiana. Area of envenoming risk by each species was estimated (Table 1), M. lebetinus and $N$. oxiana are identified with largest $\left(362,558 \mathrm{~km}^{2}\right)$ and smallest $\left(121,803 \mathrm{~km}^{2}\right)$ area, respectively.

\section{Discussion}

With this research the first snakebite envenoming risk model was produced at fine resolution $\left(\sim 1 \mathrm{~km}^{2}\right)$ in Iran by modeling and multiplying habitat suitability of four medically important venomous snakes which are responsible for the most snakebite incidents in the country ${ }^{18}$. Northeastern parts of Iran were identified to have highest snakebite risk in the country. Our results showed 51,657 villages are at the risk of envenoming from $P$. persicus which is not in concordance with our hypothesis that states that the highest number of villages are at risk of envenoming form E. carinatus. Results showed that thousands of villages are located in suitable ranges of the four venomous snakes. These villages and villagers are at risk of envenoming from the local species. The snakebite risk model shows which parts of Iran are at risk of envenoming from two, three or even four of snakes. All provinces of Iran, except those in the northwest of the country, are at risk of envenoming from at least two venomous snakes. This highlights importance of snakebite envenoming as public health problem in Iran.

Under climate change some venomous species may expand their distribution ranges ${ }^{57,58,60}$, thus, envenoming risk will likely vary ${ }^{12,17,61}$. For instance, Nori et al. ${ }^{12}$ modelled distribution of five venomous snakes in Argentina for 2030 and 2080. They found that the snakes' suitable climate spaces will increase in human populated areas of the country. In another study, Zacarias and Loyola ${ }^{58}$ modelled current and future distributions of 13 snakes in Mozambique and showed that venomous snake distribution will change under climate change. They concluded patterns of snakebite risk may change due to climatic changes ${ }^{58}$. Results of current research revealed that 

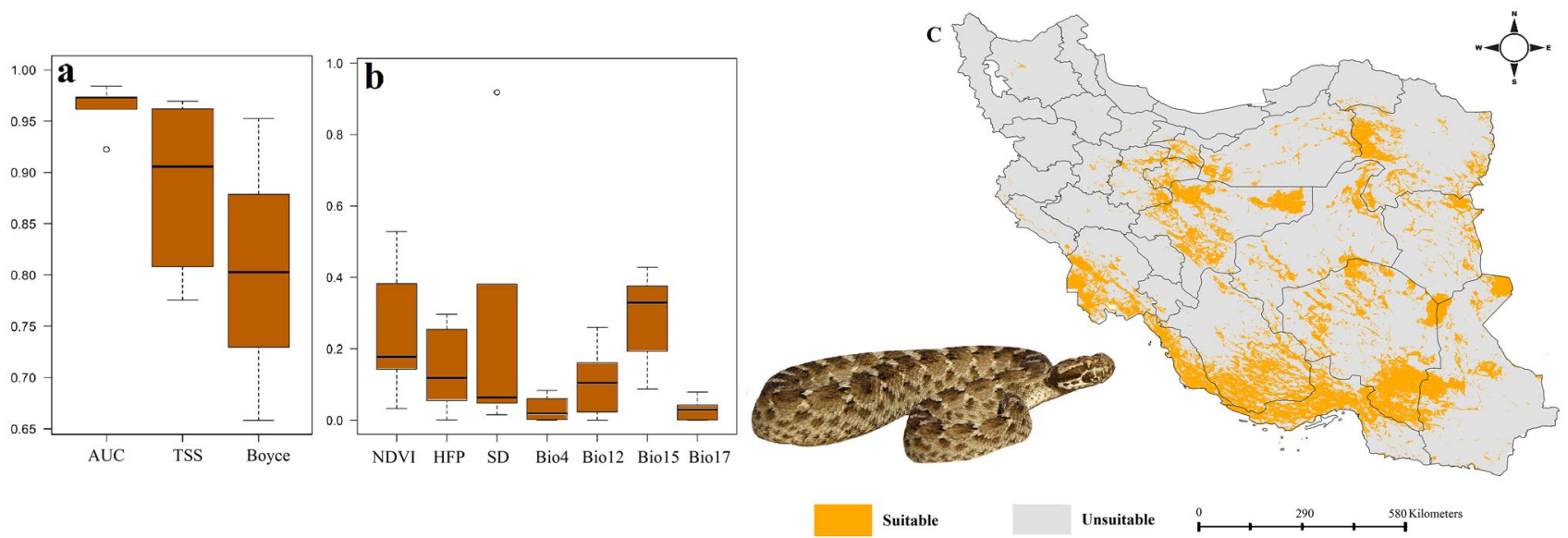

Figure 1. Variables importance (a), models performance (b) and habitat suitability model (c) of Echis carinatus in Iran. Map was generated using QGIS 3.4.1 (https://www.qgis.org).
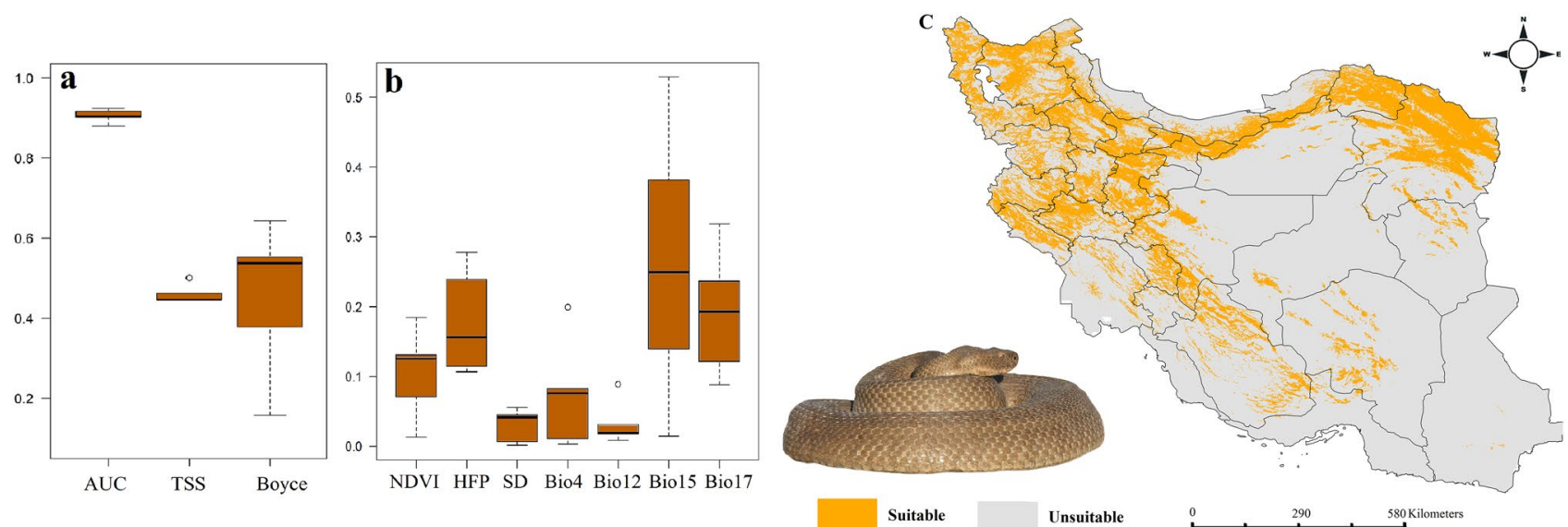

Figure 2. Variables importance (a), models performance (b) and habitat suitability (c) of Macrovipera lebetinus in Iran. Map was generated using QGIS 3.4.1 (https://www.qgis.org).
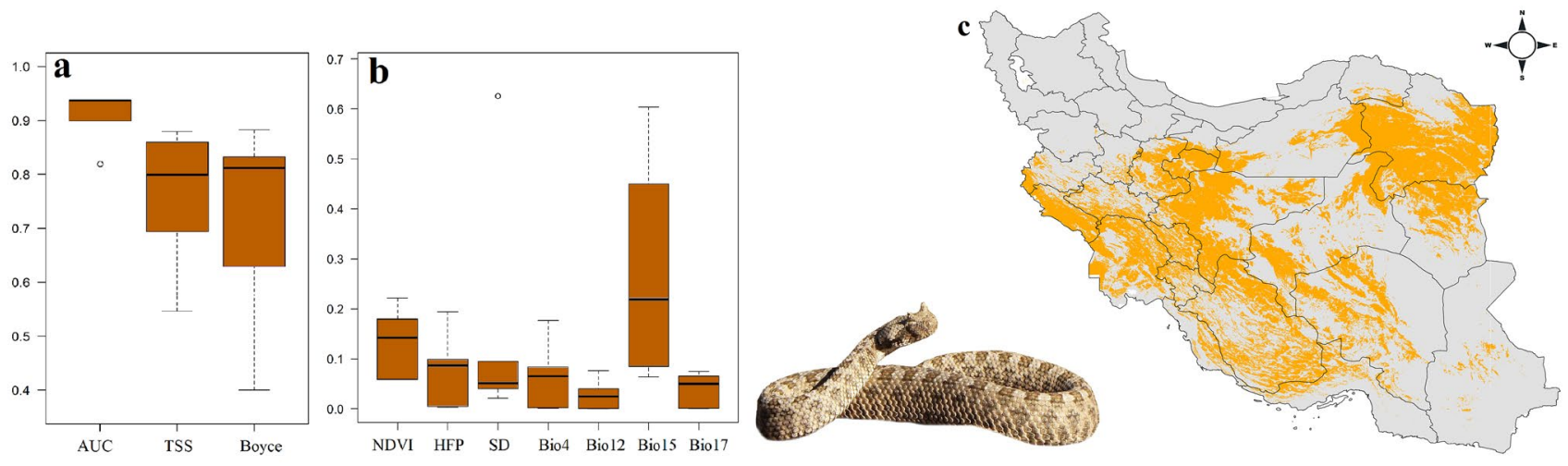

Suitable

Unsuitable

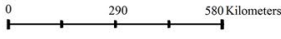

Figure 3. Variables importance (a), models performance (b) and habitat suitability (c) of Pseudocerastes persicus in Iran. Map was generated using QGIS 3.4.1 (https://www.qgis.org). 


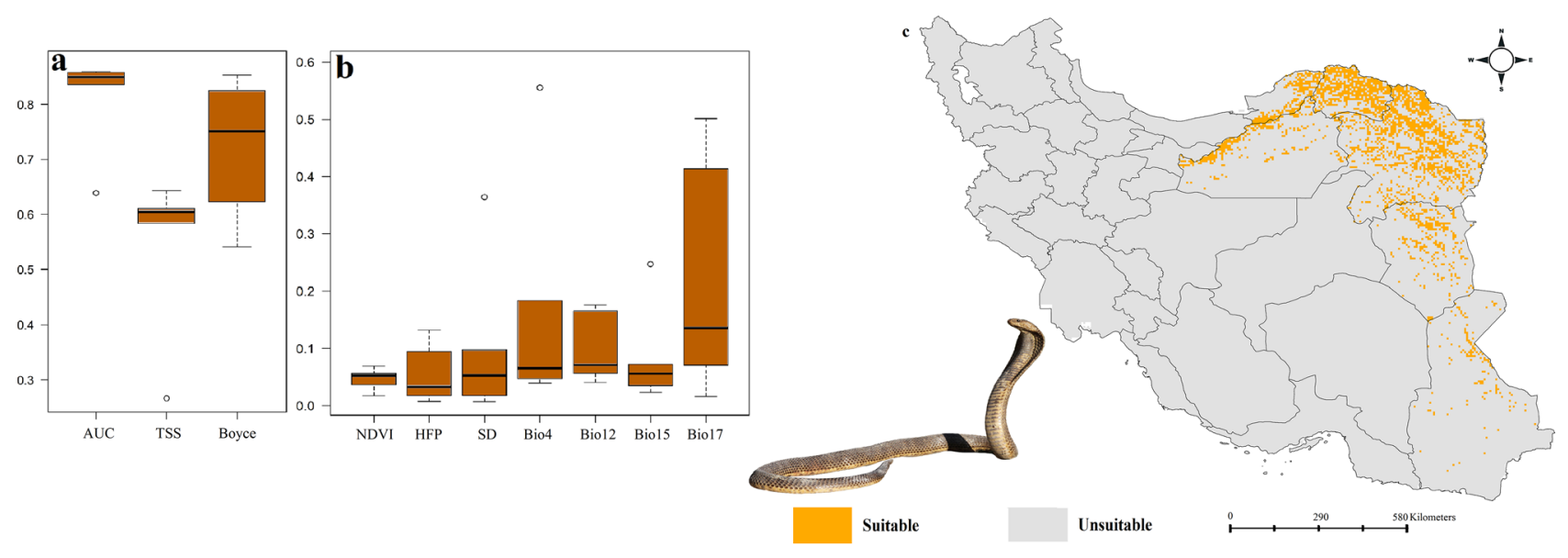

Figure 4. Variables importance (a), models performance (b) and habitat suitability (c) of Naja oxiana in Iran. Map was generated using QGIS 3.4.1 (https://www.qgis.org).

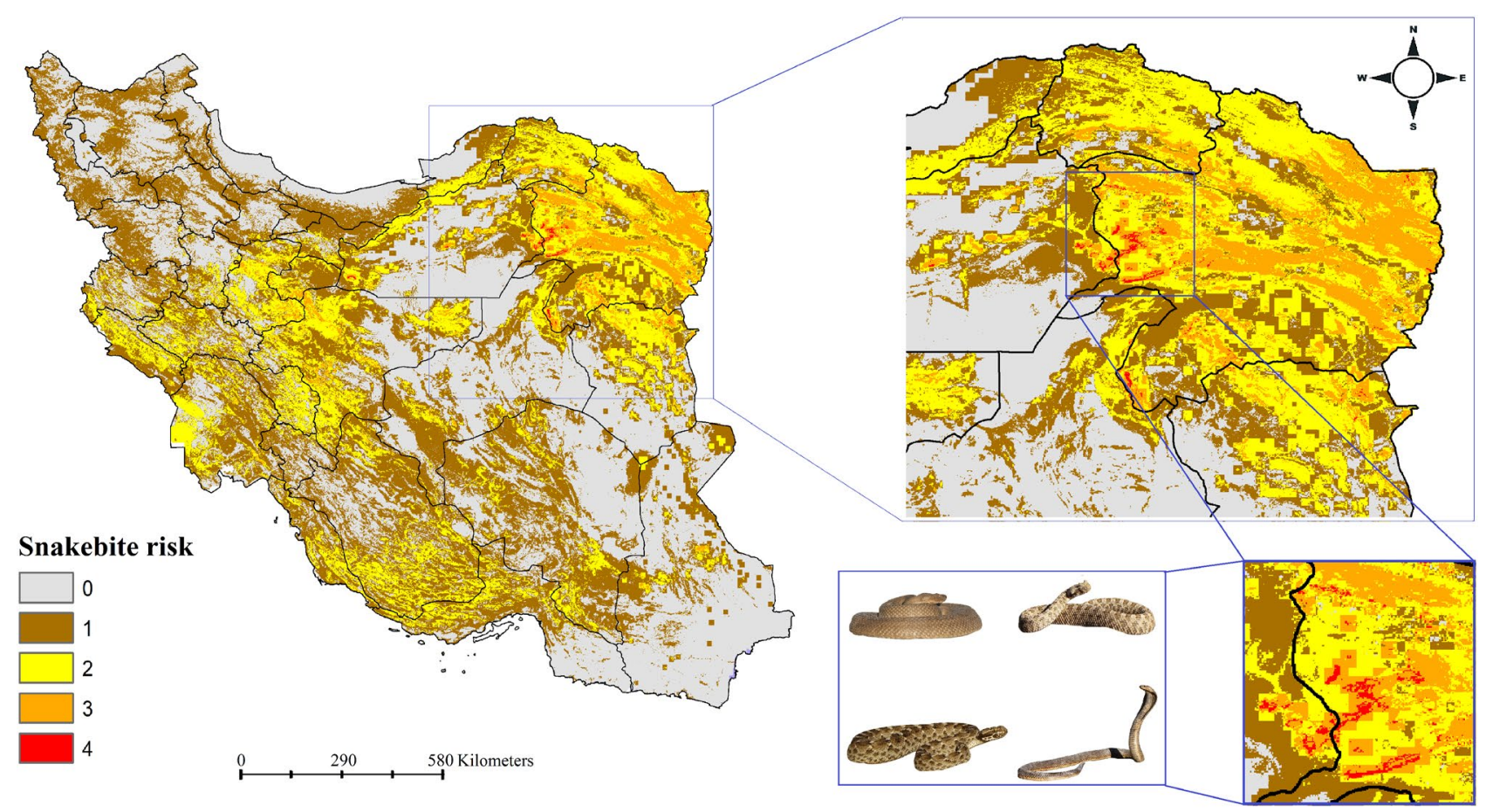

Figure 5. Snakebite risk model in Iran. The snakebite risk model was developed based on combined habitat suitability models' of Macrovipera lebetinus, Echis carinatus, Pseudocerastes persicus and Naja oxiana. Map was generated using QGIS 3.4.1 (https://www.qgis.org).

\begin{tabular}{|l|l|l|l|}
\hline Species & Villages at high risk & Villages at moderate risk & Area \\
\hline Macrovipera lebetinus & 9824 & 41,288 & 362,558 \\
\hline Echis carinatus & 5917 & 24,422 & 321,089 \\
\hline Pseudocerastes persicus & 2150 & 49,507 & 655,415 \\
\hline Naja oxiana & 3091 & 9033 & 121,803 \\
\hline
\end{tabular}

Table 1. Area $\left(\mathrm{km}^{2}\right)$ and number of villages that are at the snakebite risk from Macrovipera lebetinus, Echis carinatus, Pseudocerastes persicus and Naja oxiana in Iran. Results are based on the ensemble models. 

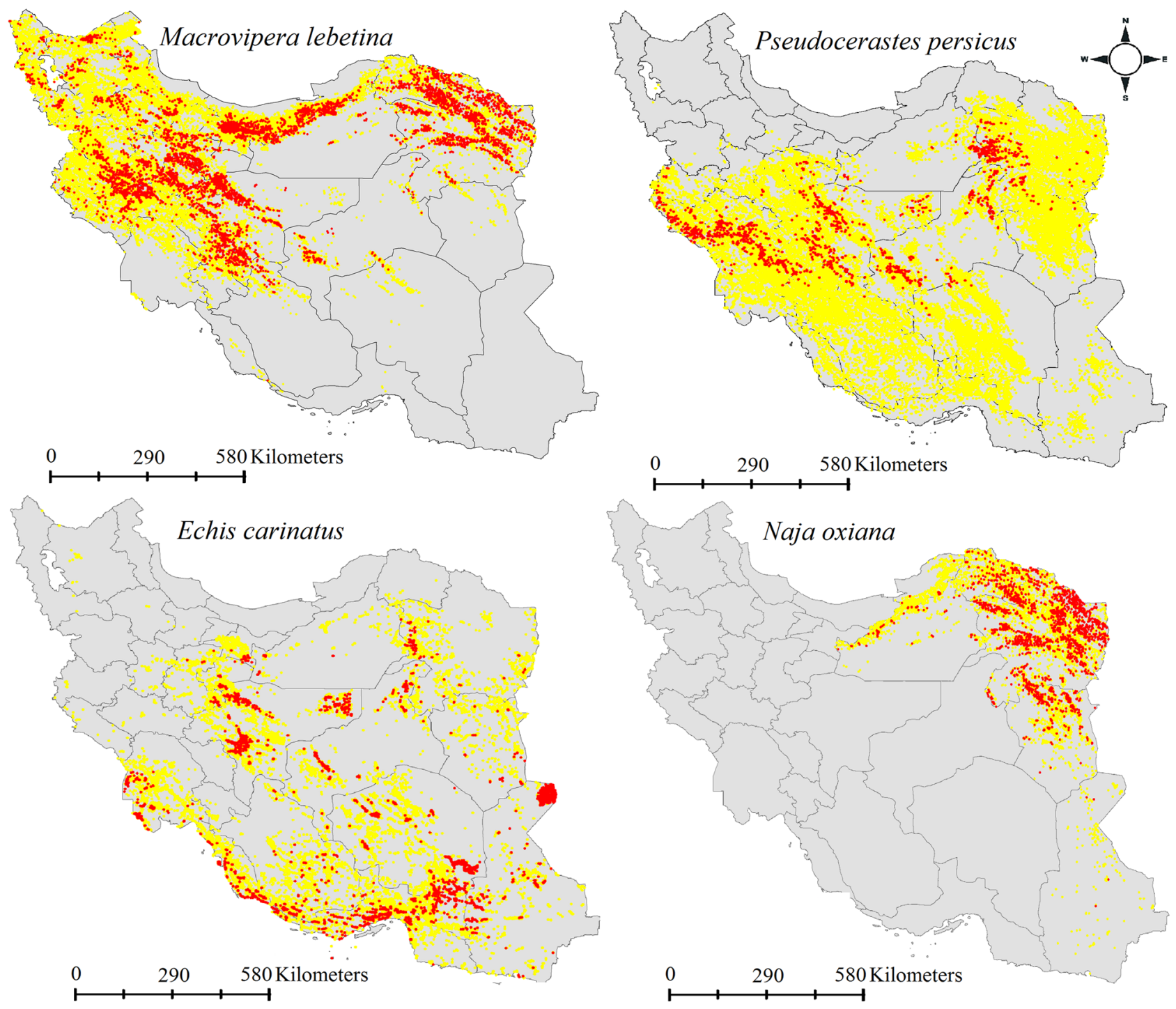

Villages at high risk

Villages at moderate risk

Figure 6. Villages at risk of envenoming from Macrovipera lebetinus, Echis carinatus, Pseudocerastes persicus and Naja oxiana. Villages at high risk are shown with red circle and villages at moderate risk are shown with yellow circle. Maps were generated using QGIS 3.4.1 (https://www.qgis.org).

climatic variables play an important role in shaping the distribution of four venomous snakes in Iran, thus their distribution may alter with changing climate. It is predicted that suitable habitats of E. carinatus will increase in $\operatorname{Iran}^{62}$. This species is an important source of snakebite in the country ${ }^{18}$ and its distributional range will likely increase under climate change ${ }^{62}$ putting more populations and human settlements at risk of envenoming by this snake until 2070.

Venomous snake populations are declining and many of them are listed by the IUCN Red List as Vulnerable, Endangered or Critically Endangered ${ }^{63}$. Conservation of snakes especially venomous snakes is a big challenge ${ }^{63}$ as it is not easy to convince people to conserve venomous snakes which are a significant cause of human mortality and morbidity ${ }^{6,14,15,56}$. It is necessary to identify areas with high risk of snakebite envenoming and prioritize those areas for snakebite risk management in each country. In this study potential risk areas were identified by using venomous snakes' habitat suitability as an indicator of snakebite risk.

One possible reason of venomous snakes' conflict with humans is the expansion of agricultural lands. For example, most of the envenoming events occur during agricultural activities in Khorasa-e-Razavi and Sistan and Baluchistan provinces (A. Khani personal observations). According to the Ministry of Health and Medical Education, rural people were victims of around $70 \%$ of snake bites in 2011 in Iran $^{18}$. Results of this study can be used to reduce snakebite and venomous snake conflicts with local people, farmers and shepherds in the country. Snakebite risk can be reduced through community education ${ }^{64-66}$. We encourage education of local people 


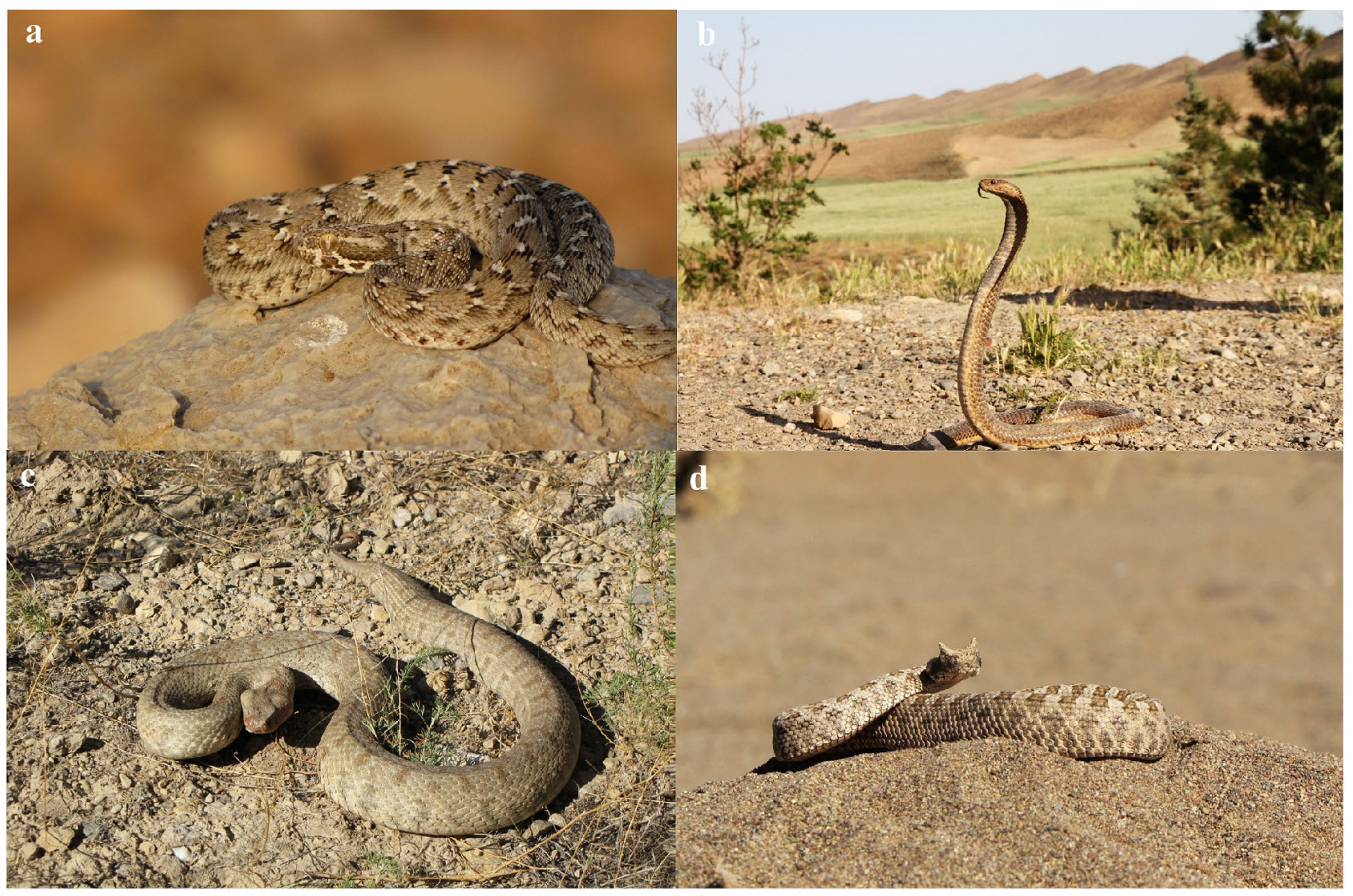

Figure 7. Photos of the four medically important venomous snake (a) Saw-scaled Viper (Echis carinatus), (b) Central Asian Cobra (Naja oxiana), (c) Levantine Viper (Macrovipera lebetinus), and (d) Persian Horned Viper (Pseudocerastes persicus) modelled in this research to map snakebite risk in Iran. Naja oxiana is listed as Data Deficient, Pseudocerastes persicus as Least Concern and Echis carinatus and Macrovipera lebetinus were not listed in the IUCN Red List ${ }^{80}$. Photos by Masoud Yousefi.

about snakebite prevention measures in areas with highest snakebite risk. There are simple solutions to prevent snakebite envenoming in areas with high risk, like villages in west of Khorasan-e-Razavi province. For example, using bed nets and protecting feet, ankles and lower legs by wearing boots can significantly reduce snakebite envenoming ${ }^{65,67}$. We also suggest that areas where snakebite envenoming risk is high should be monitored to determine envenoming events and villagers in these areas must always have access to antivenom supplies ${ }^{14}$.

Species distribution models are becoming important tools in public health research ${ }^{12,17,68-77}$. We encourage public hearth researchers to apply SDMs in developing snakebite risk map using venomous snakes' habitat suitability as an indicator, especially in data poor regions of the world ${ }^{51-53,78}$. Our approach has the potential for practical application in other countries with high snakebite risk.

\section{Materials and methods}

Occurrence data. Distribution records of the M. lebetinus, E. carinatus, P. persicus and N. oxiana (Fig. 7) were collected through long-term fieldwork and opportunistic observations from 2005 to 2019, and from published papers (Appendix S1). These four snakes were selected because they are responsible for the most snakebite incidents in $\operatorname{Iran}^{18}$ and have the widest distribution range across the country ${ }^{19,79}$. By combining presence records from the two sources 89 distribution records were obtained for M. lebetinus, 68 records for E. carinatus, 54 records for P. persicus and 37 records for N. oxiana (Fig. 8 and Table S1).

Environmental data. Seven environmental variables (Table 2) related to climate, topography, vegetation, and human footprint were used to develop the four snakes' habitat suitably models ${ }^{12,17,56,81-84}$. Climatic variables were downloaded from the WorldClim database at 30-s spatial resolution ${ }^{85}$. Normalized Difference Vegetation Index (NDVI) ${ }^{86}$ was considered as an indicator of resource availability directly for snakes or indirectly for their prey. Snakebite risk is associated with human population density and activities ${ }^{56}$, thus, human footprint index was included in models ${ }^{83,84}$. Human footprint index was produced by combining data on the extent of built environments, population density, electric infrastructure, crop lands, pasture lands, roads, railways, and navigable waterways ${ }^{83,84}$. Topographic heterogeneity was used as topography variable by measuring the standard deviation of elevation values in area grid cells of $1 \mathrm{~km}^{2}$ from a $90 \mathrm{~m}$ resolution in the Raster package ${ }^{87}$. Elevation layer was obtained from the Shuttle Radar Topography Mission (SRTM) elevation model ${ }^{88}$. A variance inflation factor 


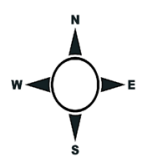

Elevation
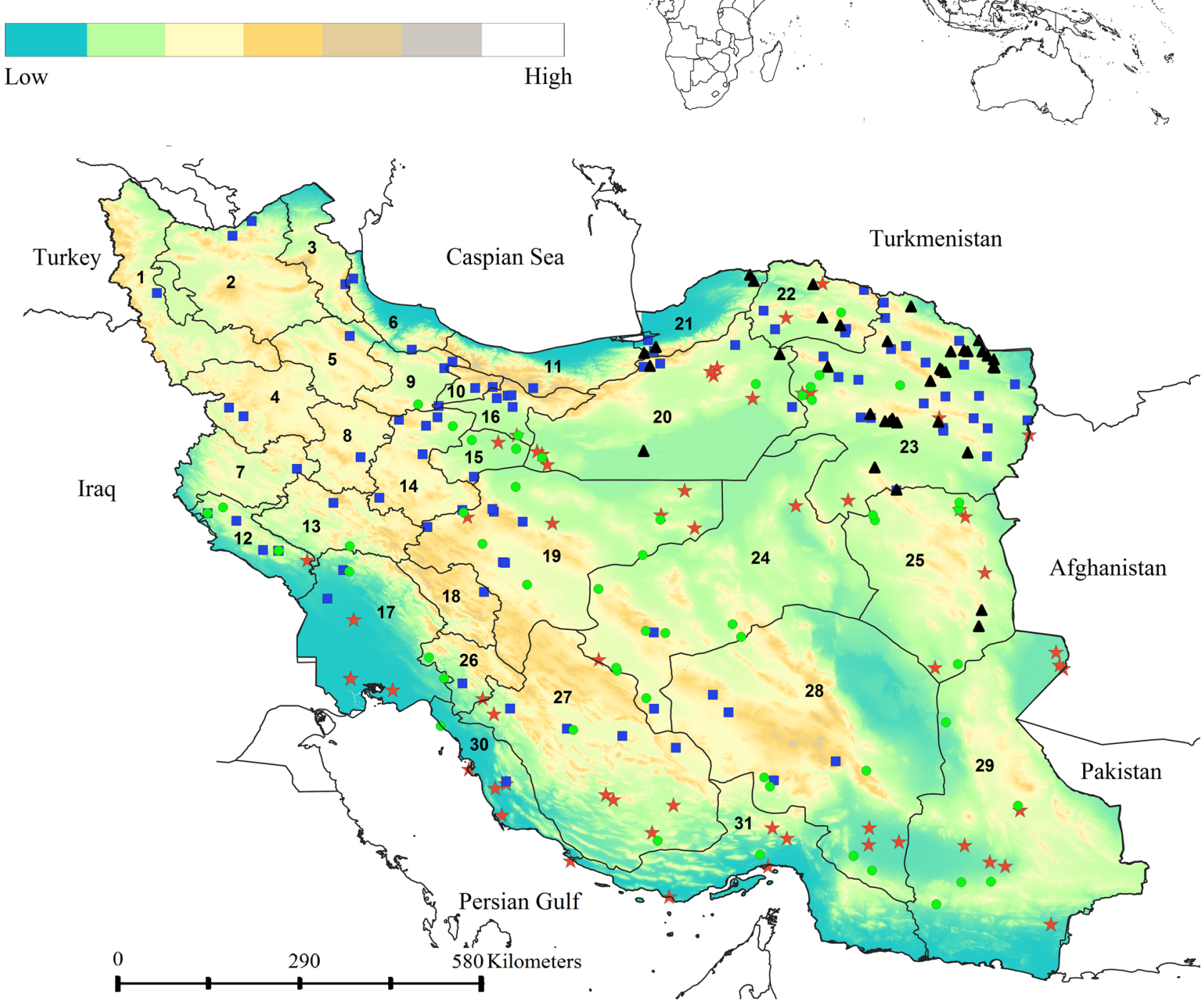

\section{Macrovipera lebetinus $\star$ Echis carinatus $\bigcirc$ Psendocerastes persicus $\Delta$ Naja oxiana}

Figure 8. Distribution records of Macrovipera lebetinus, Echis carinatus, Naja oxiana, and Pseudocerastes persicus in a topographic overview of Iran. Provinces numbers should read as follows; (1) West Azerbaijan, (2) East Azerbaijan, (3) Ardabil, (4) Kurdistan, (5) Zanjan, (6) Gilan, (7) Kermanshah, (8) Hamedan, (9) Qazvin, (10) Alborz, (11) Mazandaran, (12) Ilam, (13) Lorestan, (14) Markazi, (15) Qom, (16) Tehran, (17) Khuzestan, (18) Chahar Mahaal and Bakhtiari, (19) Isfahan, (20) Semnan, (21) Golestan, (22) Khorasan-e-Shomali (Northern Khorasan), (23) Khorasan-e-Razavi, (24) Yazd, (25) Khorasan-e-Jonobi (Southern Khorasan), (26) Kohgiluyeh and Boyer-Ahmad, (27) Fars, (28) Kerman, (29) Sistan and Baluchestan, (30) Bushehr, (31) Hormozgan. Map was generated using QGIS 3.4.1 (https://www.qgis.org). 


\begin{tabular}{|l|l|l|}
\hline Variable & Description (abbreviation) and references & VIF \\
\hline \multirow{4}{*}{ Climate } & Temperature seasonality (bio4) $^{85}$ & 1.438 \\
\cline { 2 - 3 } & Annual precipitation (bio12) $^{85}$ & 2.871 \\
\cline { 2 - 3 } & Precipitation seasonality (bio15) & 2.389 \\
\cline { 2 - 3 } & Precipitation of driest quarter (bio17) & 3.049 \\
\hline Topography & Topographic heterogeneity (SD) & 1.315 \\
\hline Vegetation & Normalized Difference Vegetation Index (NDVI) & 3.33 \\
\hline Anthropogenic & Human Footprint (HFP) & 1.466 \\
\hline
\end{tabular}

Table 2. Environmental variables were used in developing habitat suitability of venomous snakes in Iran.

$(\mathrm{VIF})^{89}$ was calculated for the variables using the 'usdm' package ${ }^{90}$ in the R environment (v.3.4.3 $)^{91}$. to ensure low collinearity among the variables (Table 2 ).

Snakebite risk mapping. An ensemble approach ${ }^{35,59}$ was applied to model habitat suitability of the M. lebetinus, E. carinatus, P. persicus and N. oxiana, using five methods: generalized boosted models (GBM $)^{92}$, generalized additive models (GAM) $)^{93}$, maximum entropy modelling (MaxEnt) ${ }^{94}$, generalized linear models $(\mathrm{GLM})^{95}$, random forest $(\mathrm{RF})^{96}$ in the biomod 2 package ${ }^{97}$. Since these methods need background data points we generated a randomly drawn sample of 10,000 background points (e.g., pseudo-absence points) from the extent of the study area using the PresenceAbsence package ${ }^{98}$. We also estimated contributions of environmental variables in shaping each venomous snake species distribution using the biomod 2 package ${ }^{97}$. We calibrated the models using $80 \%$ of records drawn randomly and used as training data, and evaluated their performance using the remaining $20 \%$ of the data (test dataset). Several metrics were introduced for assessing performance of habitat suitability models ${ }^{34,99-101}$. But it is not certain that which metrics are best for determining habitat suitability models' performance ${ }^{34}$. Thus, we applied three well known metrics to assess the produced habitat suitability models' performances. The true skills statistic (TSS), area under the receiver operating characteristic curve (AUC), and the Boyce index ${ }^{34,99-101}$. According to literature ${ }^{34,101}$, Boyce index and TSS values range from -1 to +1 , where +1 indicates perfect performance and value of zero meaning random predictions. AUC values range from 0 to 1 , a value of 0.5 indicates that the performance of the model is not better than random, while values closer to 1.0 indicate better model performance ${ }^{34,99,100}$. Then areas associated with high snakebite risk in Iran were identified by multiplying habitat suitability models of the four species.

To quantify snakebite risk in Iran in more detail number of villages that are at risk of envenoming from the four snakes determined and area of snakebite risk calculated in the Raster package ${ }^{87}$. For this continuous habitat suitability models were converted to suitable/unsuitable maps using maximum test sensitivity with a specificity threshold ${ }^{102}$, and then overlaying 185,000 (population in these villages range from less than 50 to 5000 individuals) villages with each snake model.

\section{Data availability}

The datasets generated and analysed during the current study are available from supplementary information and also the corresponding author on reasonable request.

Received: 3 July 2020; Accepted: 5 October 2020

Published online: 22 October 2020

\section{References}

1. Chippaux, J. P. Snake-bites: appraisal of the global situation. Bull. World Health Organ. 76, 515.9868843 (1998).

2. White, J. Bites and stings from venomous animals: a global overview. Ther. Drug Monit. 22, 65-68 (2000).

3. Juckett, G. \& Hancox, J. G. Venomous snakebites in the United States: management review and update. Am. Fam. Phys. 65, 1367-1378 (2002).

4. Kasturiratne, A. et al. Estimates of disease burden due to land-snake bite in Sri Lankan hospitals. Southeast. Asian. J. Trop. Med. Public Health 36, 733 (2005).

5. Gutiérrez, J. M., Theakston, R. D. G. \& Warrell, D. A. Confronting the neglected problem of snake bite envenoming: the need for a global partnership. PLoS Med. 3, e150 (2006).

6. Kasturiratne, A. et al. The global burden of snakebite: a literature analysis and modeling based on regional estimates of envenoming and deaths. PLoS Med. 5, 1591-1604 (2008).

7. Cruz, L. S., Vargas, R. \& Lopes, A. A. Snakebite envenomation and death in the developing world. Ethn. Dis. 19, 42 (2009).

8. Warrell, D. Snake bite. Lancet 375, 77-88 (2010).

9. Chippaux, J. P. Estimate of the burden of snakebites in sub-Saharan Africa: a meta-analytic approach. Toxicon 57, 586-599 (2011).

10. Gutiérrez, J. M. Snakebite envenoming: a public health perspective. In Public Health-Methodology, Environmental and Systems Issues (ed. Maddock, J.) (InTech, London, 2012).

11. Hansson, E., Sasa, M., Mattisson, K., Robles, A. \& Gutiérrez, J. M. Using geographical information systems to identify populations in need of improved accessibility to antivenom treatment for snakebite envenoming in Costa Rica. PLoS Negl. Trop. Dis. 7, e2009 (2013).

12. Nori, J., Carrasco, P. A. \& Leynaud, G. C. Venomous snakes and climate change: ophidism as a dynamic problem. Clim. Change 122, 67-80 (2014).

13. Chippaux, J. P. Incidence and mortality due to snakebite in the Americas. PLoS Negl. Trop. Dis. 11, e0005662-e5739 (2017). 
14. Longbottom, J. et al. Vulnerability to snakebite envenoming: a global mapping of hotspots. Lancet 392, 673-684 (2018).

15. Gutiérrez, J. M. et al. Snakebite envenoming. Nature 3, 17063 (2017).

16. Alirol, E., Sharma, S. K., Bawaskar, H. S., Kuch, U. \& Chappuis, F. Snake bite in South Asia: a review. PLoS Negl. Trop. Dis. 4, e603 (2010).

17. Yañez-Arenas, C., Díaz-Gamboa, L., Patrón-Rivero, C., López-Reyes, K. \& Chiappa-Carrara, X. Estimating geographic patterns of ophidism risk in Ecuador. Neotrop. Biodivers. 4, 55-61 (2018).

18. Dehghani, R., Fathi, B., Panjeh Shahi, M. \& Jazayeri, M. Ten years of snakebites in Iran. Toxicon 90, 291-298 (2014).

19. Latifi, M. The Snakes of Iran (Department of Environment, Tehran, 2000).

20. Monzavi, S. M., Dadpour, B. \& Afshari, R. Snakebite management in Iran: devising a protocol. J. Res. Med. Sci. 19, 153-163 (2014).

21. Rastegar-Pouyani, E. et al. A re-evaluation of taxonomic status of Montivipera (Squamata: Viperidae) from Iran using a DNA barcoding approach. Biochem. Syst. Ecol. 57, 350-356 (2014).

22. Oraie, H. et al. Molecular and morphological analyses have revealed a new species of blunt-nosed viper of the genus Macrovipera in Iran. Salamandra 54, 233-238 (2018).

23. Moradi, N., Rastegra-Pouyani, N. \& Rastegra-Pouyani, E. Geographic variation in the morphology of Macrovipera lebetina (Linnaeus, 1758) (Ophidia: Viperidae) in Iran. Acta Herpetol. 9, 187-202 (2014).

24. Fathinia, B., Rastegar-Pouyani, N., Rastegar-Pouyani, E., Toodeh-Dehghan, F. \& Rajabizadeh, M. Molecular systematics of the genus Pseudocerastes (Ophidia: Viperidae) based on the mitochondrial cytochrome b gene. Turk. J. Zool. 38, 575-581 (2014).

25. Behrooz, R. et al. Habitat modeling and conservation of the endemic Latifi's viper (Montivipera latifii) in Lar National Park Northern Iran. Herpetol. Conserv. Biol. 10, 572-582 (2015).

26. Khani, Sh., Kami, H. G. \& Rajabizadeh, M. Geographic variation of Gloydius halys caucasicus (Serpentes: Viperidae) in Iran. Zool. Middle East. 63, 303-310 (2017).

27. Fathinia, B., Rastegar-Pouyani, N. \& Rastegar-Pouyani, E. Molecular phylogeny and historical biogeography of genera Eristicophis and Pseudocerastes (Ophidia, Viperidae). Zool. Scr. 47, 673-685 (2018).

28. Rastegar-Pouyani, E., Oraie, H., Khosravani, A. \& Akbari, A. Phylogenetic position of Iranian pitvipers (Viperidae, Crotalinae, Gloydius) inferred from mitochondrial cytochrome b sequences. Trop. Zool. 31, 55-67 (2018).

29. Eslamian, L. et al. Snake bite in Northwest Iran: a retrospective study. J. Anal. Res. Clin. Med. 4, 133-138 (2016).

30. Dehghani, R., Rabani, D., Panjeh-Shahi, M., Jazayeri, M. \& Sabahi Bidgoli, M. Incidence of snake bite in Kashan, IR Iran during an eight-year period (2004-2011). Arch. Trauma Res. 1, 67-71 (2012).

31. Farzaneh, E. et al. Epidemiological study of snakebites in Ardabil Province (Iran). Electron. Phys. 9, 3986-3990 (2017).

32. Ebrahimi, V., Hamdami, E., Khademian, M. H., Moemenbellah-Fard, M. D. \& Vazirianzadeh, B. Epidemiologic prediction of snake bites in tropical south Iran: using seasonal time series methods. Clin. Epidemiol. Glob. Health 6, 208-215 (2018).

33. Guisan, A. \& Thuiller, W. Predicting species distribution: offering more than simple habitat models. Ecol. Lett. 8, 993-1009 (2005).

34. Guisan, A., Thuiller, W. \& Zimmermann, N. E. Habitat Suitability and Distribution Models: With Applications in R (Cambridge University Press, Cambridge, 2017).

35. Araújo, M. B. et al. Standards for distribution models in biodiversity assessments. Sci. Adv. 5, eaat4858 (2019).

36. Milanesi, P., Holderegger, R., Caniglia, R., Fabbri, E. \& Randi, E. Different habitat suitability models yield different least-cost path distances for landscape genetic analysis. Basic Appl. Ecol. 17, 61-71 (2015).

37. Moradi, S., Sheykhi Ilanloo, S., Kafash, A. \& Yousefi, Y. Identifying high-priority conservation areas for avian biodiversity using species distribution modeling. Ecol. Indic. 97, 159-164 (2019).

38. Farrell, A. et al. Machine learning of large-scale spatial distributions of wild turkeys with high-dimensional environmental data. Ecol. Evol. 9, 5938-5949 (2019).

39. Kalle, R., Ramesh, T., Qureshi, Q. \& Sankar, K. Predicting the distribution pattern of small carnivores in response to environmental factors in the Western Ghats. PLoS ONE 8, e79295 (2013).

40. Bradie, J. \& Leung, B. A. quantitative synthesis of the importance of variables used in MaxEnt species distribution models. J. Biogeogr. 44, 1344-1361 (2017).

41. Ashoori, A. et al. Habitat modeling of the common pheasant Phasianus colchicus (Galliformes: Phasianidae) in a highly modified landscape: application of species distribution models in the study of a poorly documented bird in Iran. Eur. Zool. J. 85, 373-381 (2018).

42. Sutton, L. J. \& Puschendorf, R. Climatic niche of the Saker Falcon Falco cherrug: predicted new areas to direct population surveys in Central Asia. Ibis 162, 27-41 (2020).

43. Andrade-Díaz, M. S. et al. Expansion of the agricultural frontier in the largest South American Dry Forest: identifying priority conservation areas for snakes before everything is lost. PLOS ONE 14, e0221901 (2019).

44. Smeraldo, S. et al. Modelling risks posed by wind turbines and power lines to soaring birds: the black stork (Ciconia nigra) in Italy as a case study. Biodivers. Conserv. 29, 1959-1976 (2020).

45. Qin, A. et al. Maxent modeling for predicting impacts of climate change on the potential distribution of Thuja sutchuenensis Franch, an extremely endangered conifer from southwestern China. Glob. Ecol. Conserv. 10, 139-146 (2017).

46. Wang, R. et al. Modeling and mapping the current and future distribution of Pseudomonas syringae pv. actinidiae under climate change in China. PLoS ONE 13, e0192153 (2018).

47. Kafash, A. et al. Climate change produces winners and losers: differential responses of amphibians in mountain forests of the Near East. Glob. Ecol. Conserv. 16, e00471 (2018).

48. Schivo, F., Bauni, V., Krug, P. \& Quintana, R. D. Distribution and richness of amphibians under different climate change scenarios in a subtropical region of South America. Appl Geogr. 103, 70-89 (2019).

49. Ashrafzadeh, M. R., Naghipour, A. A., Haidarian, M., Kusza, S. \& Pilliod, D. S. Effects of climate change on habitat and connectivity for populations of a vulnerable, endemic salamander in Iran. Glob. Ecol. Conserv. 19, e00637 (2019).

50. Yousefi, M., Jouladeh-Rodbar, A. \& Kafash, A. Using endemic freshwater fishes as proxies of their ecosystems to identify high priority rivers for conservation under climate change. Ecol. Indic. 112, 106137 (2020).

51. Segura, S., Coppens d’Eeckenbrugge, G., López, L., Grum, M. \& Guarino, L. Mapping the potential distribution of five species of Passiflora in Andean countries. Genet. Resour. Crop Evol. 50, 555-566 (2003).

52. Rebelo, H. \& Jones, G. Ground validation of presence-only modelling with rare species: a case study on barbastelles Barbastella barbastellus (Chiroptera: Vespertilionidae). J. Appl. Ecol. 47, 410-420 (2010).

53. Rhoden, C. M., Peterman, W. E. \& Taylor, C. A. Maxent-directed field surveys identify new populations of narrowly endemic habitat specialists. PeerJ 5, e3632 (2017).

54. Bertolino, S. et al. Spatially-explicit models as tools for implementing effective management strategies for invasive alien mammals. Mamm. Rev. 50, 187-199 (2020).

55. Pauli, B. P. et al. Human habitat selection: using tools from wildlife ecology to predict recreation in natural landscapes. Nat. Areas J. 39, 142-149 (2019).

56. Yañez-Arenas, C., Peterson, A. T., Mokondoko, P., Rojas-Soto, O. \& Martínez-Meyer, E. The use of ecological niche modeling to infer potential risk areas of snakebite in the Mexican State of Veracruz. PLoS ONE 9, e100957 (2014). 
57. Yañez-Arenas, C., Peterson, A. T., Rodriguez-Medina, K. \& Barve, N. Mapping current and future potential snakebite risk in the new world. Clim. Change 134, 697-711 (2016).

58. Zacarias, D. \& Loyola, R. Climate change impacts on the distribution of venomous snakes and snakebite risk in Mozambique. Clim. Change 152, 195 (2019).

59. Araújo, M. B. \& New, M. Ensemble forecasting of species distributions. Trends Ecol. Evol. 22, 42-47 (2007).

60. Yousefi, M. et al. Climate change is a major problem for biodiversity conservation: a systematic review of recent studies in Iran. Contemp. Probl. Ecol. 12, 394-403 (2019).

61. Hannah, L. Climate Change Biology 2nd edn. (Academic Press, Cambridge, 2015).

62. Yousefi, M. \& Kafash, A. Venomous snakes of Iran under climate change. In SCCS Europe-4th Hungarian Student Conference on Conservation Science, 4-8 September (2018).

63. Maritz, B. et al. Identifying global priorities for the conservation of vipers. Biol. Conserv. 204, 94-102 (2016).

64. Sharma, S. K. et al. Effectiveness of rapid transport of victims and community health education on snake bite fatalities in rural Nepal. Am. J. Trop. Med. Hyg. 89, 145-150 (2013).

65. WHO. Guidelines for the Management of Snakebites (World Health Organization, Geneva, 2016).

66. Trogridou, A. Prevention is Better Than Cure: Snakebite Education in India (Episthmes Agogis, 2018).

67. Chappuis, F., Sharma, S. K., Jha, N., Loutan, L. \& Bovier, P. A. Protection against snake bites by sleeping under a bed net in southeastern Nepal. Am. J. Trop. Med. Hyg. 77, 197-199 (2007).

68. Khatchikian, C., Sangermano, F., Kendell, D. \& Livdahl, T. Evaluation of species distribution model algorithms for fine-scale container-breeding mosquito risk prediction. Med. Vet. Entomol. 25, 268-275 (2011).

69. Escobar, L. E. et al. Ecology and geography of transmission of two bat-borne rabies lineages in Chile. PLoS Negl. Trop. Dis. 7, e2577 (2013).

70. Du, Z. et al. Ecological niche modeling for predicting the potential risk areas of severe fever with thrombocytopenia syndrome. Int. J. Infect. Dis. 26, 1-8 (2014).

71. Peterson, T. Mapping Disease Transmission Risk: Enriching Models Using Biogeography and Ecology (Johns Hopkins University Press, Baltimore, 2014).

72. Escobar, L. E. \& Craft, M. E. Advances and limitations of disease biogeography using ecological niche modeling. Front. Microbiol. 7, 1174 (2016)

73. Escobar, L. E. et al. Ecological approaches in veterinary epidemiology: mapping the risk of bat-borne rabies using vegetation indices and night-time light satellite imagery. Vet. Res. 46, 92 (2015).

74. Nyakarahuka, L. et al. Ecological niche modeling for filoviruses: a risk map for Ebola and Marburg virus disease outbreaks in Uganda.PLoS Curr. (2017). Edition 1 2017.https://doi.org/10.1371/currents.outbreaks.07992a87522elf229c7cb023270a2af1.

75. Soucy, J. P. R. et al. High-resolution ecological niche modeling of Ixodes scapularis ticks based on passive surveillance data at the Northern Frontier of Lyme disease emergence in North America. Vector Borne Zoonotic Dis. 18, 235-242 (2018).

76. Little, E. A. H. et al. Predicting spatiotemporal patterns of Lyme disease incidence from passively collected surveillance data for Borrelia burgdorferi sensu lato-infected Ixodes scapularis ticks. Ticks. Ticks Tick Borne Dis. 10, 970-980 (2019).

77. Johnson, E. E., Escobar, L. E. \& Zambrana-Torrelio, C. An ecological framework for modeling the geography of disease transmission. Trends Ecol. Evol. 34, 655-668 (2019).

78. Yousefi, M. et al. Upward altitudinal shifts in habitat suitability of mountain vipers since the last glacial maximum. PLoS ONE 10, e0138087 (2015)

79. Rajabizadeh, M. Snakes of Iran (IranShenasi Publishing, Tehran, 2017).

80. IUCN. The IUCN Red List of Threatened Species. Version 2019.3. https://www.iucnredlist.org. Accessed 10 March 2020 (2019).

81. Pettorelli, N. et al. Using the satellite-derived NDVI to assess ecological responses to environmental change. Trends Ecol. Evol. 20, 503-510 (2005).

82. Terribile, L. C. et al. Global richness patterns of venomous snakes reveal contrasting influences of ecology and history in two different clades. Oecologia 159, 617 (2009).

83. Venter, O. et al. Sixteen years of change in the global terrestrial human footprint and implications for biodiversity conservation. Nat. Commun. 7, 12558 (2016).

84. Venter, O. et al. Global terrestrial human footprint maps for 1993 and 2009. Sci. Data 3, 160067 (2016).

85. Fick, S. E. \& Hijmans, R. J. WorldClim 2: new 1-km spatial resolution climate surfaces for global land areas. Int. J. Climatol. 37, 4302-4315 (2017)

86. Broxton, P. D., Zeng, X., Schefic, W. \& Troch, P. A. A MODIS-Based global 1-km maximum green vegetation fraction dataset. J. Appl. Meteorol. Clim. 53, 1996-2004 (2014).

87. Hijmans, R. J. Raster: Geographic Data Analysis and Modeling. R Package (2015).

88. Jarvis, A., Reuter, H. I., Nelson, A. \& Guevara, E. Hole-filled SRTM for the globe Version 4. Available from the CGIAR-CSI SRTM 90m Database. https://srtm.csi.cgiar.org. Accessed on 15 Apr 2015 (2008).

89. Quinn, G. P. \& Keough, M. J. Experimental Designs and Data Analysis for Biologists (Cambridge University Press, Cambridge, 2002).

90. Naimi, B. Uncertainty Analysis for Species Distribution Models. R Package Version 1.1-15 (2015).

91. R Core Team. R: A Language and Environment for Statistical Computing (R Core Team, Vienna, 2017).

92. Ridgeway, G. The state of boosting. Comput. Stat. 31, 172-181 (1999).

93. Hastie, T. J. \& Tibshirani, R. Generalized Additive Models (Chapman and Hall, London, 1990).

94. Phillips, S. J., Anderson, R. P. \& Schapire, R. E. Maximum entropy modeling of species geographic distributions. Ecol. Model. 190, 231-259 (2006).

95. McCullagh, P. \& Nelder, J. A. Generalized Linear Models (Chapman and Hall, London, 1989).

96. Breiman, L. Random forests. Mach. Learn. 45, 5-32 (2001).

97. Thuiller, W., Georges, D., Engler, R. \& Breiner, F. biomod2: Ensemble Platform for Species Distribution Modeling. R package version 3.3-7 (2016).

98. Freeman, E. A. \& Moisen, G. PresenceAbsence: an r package for presence absence model analysis. J. Stat. Softw. 23, 1-31 (2008).

99. Swets, J. A. Measuring the accuracy of diagnostic systems. Science 240, 1285-1293 (1988).

100. Fielding, A. H. \& Bell, J. F. A review of methods for the assessment of prediction errors in conservation presence-absence models. Environ. Conserv. 24, 38-49 (1997).

101. Boyce, M. S., Vernier, P. R., Nielsen, S. E. \& Schmiegelow, F. K. A. Evaluating resource selection functions. Ecol. Model. 157, 281-300 (2002)

102. Liu, C., White, M. \& Newell, G. Selecting thresholds for the prediction of species occurrence with presence-only data. J. Biogeogr. 40, 778-789 (2013).

\section{Acknowledgements}

We thank Ollie Thomas and Daniel Kane for improving the English of the manuscript. 


\section{Author contributions}

M.Y. conceived this study, M.Y. A.Kh. and A.K. collected distribution data, A.K. performed statistical analyses. M.Y. wrote the manuscript with inputs from A.K. A.Kh. and N.N. All authors read, revised, and approved the final manuscript.

\section{Competing interests}

The authors declare no competing interests.

\section{Additional information}

Supplementary information is available for this paper at https://doi.org/10.1038/s41598-020-74682-W.

Correspondence and requests for materials should be addressed to A.K.

Reprints and permissions information is available at www.nature.com/reprints.

Publisher's note Springer Nature remains neutral with regard to jurisdictional claims in published maps and institutional affiliations.

(c) (i) Open Access This article is licensed under a Creative Commons Attribution 4.0 International License, which permits use, sharing, adaptation, distribution and reproduction in any medium or format, as long as you give appropriate credit to the original author(s) and the source, provide a link to the Creative Commons licence, and indicate if changes were made. The images or other third party material in this article are included in the article's Creative Commons licence, unless indicated otherwise in a credit line to the material. If material is not included in the article's Creative Commons licence and your intended use is not permitted by statutory regulation or exceeds the permitted use, you will need to obtain permission directly from the copyright holder. To view a copy of this licence, visit http://creativecommons.org/licenses/by/4.0/.

(c) The Author(s) 2020 